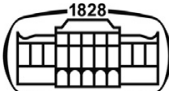

AKADÉMIAI KIADÓ

Acta Microbiologica et Immunologica Hungarica

DOI:

$10.1556 / 030.2020 .01080$

(c) 2020 The Author(s)

\title{
A simplified in vitro model for investigation of the antimicrobial efficacy of various antiseptic agents to prevent peri-implantitis
}

\author{
ANNAMÁRIA VENKEI ${ }^{1 *}$ (D), GABRIELLA EÖRDEGH ${ }^{2}$, \\ KINGA TURZÓ ${ }^{3}$, EDIT URBÁN ${ }^{1}$, and KRISZTINA UNGVÁRI ${ }^{2}$ \\ ${ }^{1}$ Institute of Clinical Microbiology, Faculty of Medicine, University of Szeged, 6725, Semmelweis u. 6, \\ Szeged, Hungary \\ ${ }^{2}$ Department of Oral Biology and Experimental Dental Research, Faculty of Dentistry, University of \\ Szeged, 6720, Tisza Lajos krt. 64, Szeged, Hungary \\ ${ }^{3}$ Dentistry Program, Medical School, University of Pécs, 7621, Dischka Gy. u. 5, Pécs, Hungary
}

Received: November 8,2019 • Accepted: January 1, 2020

\section{ORIGINAL ARTICLE}

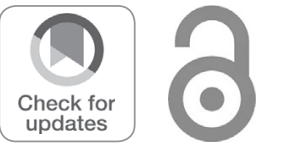

\begin{abstract}
The biofilm formation by oral bacteria on the implant surface is one of the most remarkable factors of peri-implant infections, which may eventually lead to bone resorption and loss of the dental implant. Therefore, the elimination of biofilm is an essential step for the successful therapy of implant-related infections. In this work we created a basic in vitro model to evaluate the antibacterial effect of three widely used antiseptics.

Commercially pure (CP4) titanium sample discs with sand blasted, acid etched, and polished surface were used. The discs were incubated with mono-cultures of Streptococcus mitis and Streptococcus salivarius. The adhered bacterial biofilms were treated with different antiseptics: chlorhexidine-digluconate (CHX), povidone-iodine (PI), and chlorine dioxide (CD) for $5 \mathrm{~min}$ and the control discs with ultrapure water. The antibacterial effect of the antiseptics was tested by colorimetric assay.

According to the results, the PI and the CD were statistically the most effective in the elimination of the two test bacteria on both titanium surfaces after 5 min treatment time. The CD showed significant effect only against $S$. salivarius.

Based on our results we conclude that PI and CD may be promising antibacterial agents to disinfecting the peri-implant site in the dental practice.
\end{abstract}

\section{KEYWORDS}

titanium, antimicrobial agents, peri-implantitis, Streptococcus mitis, Streptococcus salivarius

\section{INTRODUCTION}

Implantation is one of the most widely applied treatment options for tooth replacement. Titanium ( $\mathrm{Ti}$ ) and $\mathrm{Ti}$ alloys are the most common choices for dental implant materials because these materials are well tolerated by human tissues and they integrate easily with the bone to allow successful osseointegration [1]. Good clinical implantation intervention depends on various factors. Bacterial colonization, biofilm formation, and consequent periimplantitis play major roles among the complications [2].

The oral microbiota is a diverse community, consisting of over 700 different bacterial and

*Corresponding author. Tel.: +36 (62) 54-5398; E-mail: venkei. annamaria@gmail.com fungal species, which can form biofilm on soft and hard surfaces, including the implant surfaces [3]. Formation of a microbial biofilm is a complex and multi-step process. Most of the pioneer colonizers, belongs to Streptococcus genus and plays key role in the formation of multilayered dental plaque in oral cavity [4]. The formation and maturation of bacterial biofilm on the surfaces of dental implant have been associated with the etiology of peri- 
implant mucositis and peri-implantitis. Peri-implantitis is one of the major causes of unsuccessful implantation, since the periodontopathogenic bacteria can penetrate from the colonized neck part of an implant along the implant body in the gingiva and deeper hard tissue region, triggering inflammation around osseointegrated implants which may result in the loss of bone around an implant $[5,6]$.

Esposito et al. [7], published in their earlier study that 8$50 \%$ of implant removal processes are due to peri-implantitis. Because of the growing number of concerned patients every year, dentists need to address the proper treatment of peri-implant infections.

Currently, the treatment of peri-implantitis is done by mechanical debridement with or without adjunctive antiseptic agents. The most suitable chemical agent for disinfecting the peri-implant region has not yet been found because of the lack of comprehensive in vitro and in vivo experiments [8]. Several disinfectants have been tested with varying success.

In our earlier study we investigated the cytotoxic effect of three different disinfectant solutions $\left(3 \% \mathrm{H}_{2} \mathrm{O}_{2}\right.$ solution, saturated citric acid $(\mathrm{pH}=1)$ and $\mathrm{CHX}$ gel) on human epithelial cells attached to Ti surfaces [9]. Connecting to our previous study in this current work we done a basic research to observe the antimicrobial effects of decontaminant agents e.g., chlorhexidine-digluconate (CHX), chlorine dioxide (CD), and povidone-iodine (PI).

CHX has been the most frequently used agent in the adjuvant treatment of peri-implantitis for years as it has a broad-spectrum antimicrobial effect, both bactericidal and bacteriostatic, depending on the applied concentration [10]. CHX can also penetrate into the biofilm to damage the incorporated bacteria [11].

$\mathrm{CD}$ is used in various fields due to the excellent bactericidal and antiviral properties [12]. It can also diffuse easily into the biofilm and destroys the microbes forming the film [13].

PI has been used as a topical antiseptic in oral surgery and periodontal practice. PI has a wide spectrum of antibacterial and antiviral effects. The information regarding its effect on biofilms is limited [14]. Furthermore, the comparisons of antibacterial effect of $\mathrm{CHX}, \mathrm{CD}$, and PI have not yet been investigated.

The oral microbiota is a very complex ecological community that hard to model exactly, since it contains a huge number of culturable and unculturable bacteria which need special demands to their viability and proliferation $[15,16]$. Our research group previously used Streptococcus strain as a model organism for dental research [17]. Therefore, in this study we also applied a simplified in vitro model and chose pioneer colonizers (Streptococcus mitis, Streptococcus salivarius) to our investigations.

\section{MATERIALS AND METHODS}

\section{Preparation of disc surfaces for the experiment}

In our experiments we used two different surface modified Ti discs. The discs (1.5 mm thick and $9 \mathrm{~mm}$ diameter) were cut from commercially pure (CP4) Ti rods (Denti System ${ }^{\circledR}$, Hungary). One type of the discs surfaces were modified by sand blasting, acid etching technique and the surfaces of the other discs were polished by the manufacturer. Before the experiments the samples were cleaned with acetone, then with $70 \%$ ethanol for $15 \mathrm{~min}$, and rinsed with ultrapure water three times. Finally, the samples were sterilized at $160{ }^{\circ} \mathrm{C}$ for $45 \mathrm{~min}$.

\section{Investigation of the antibacterial activity of the three different antiseptic agents on mono-species biofilms}

S. mitis and S. salivarius isolates from patients who had clinical symptoms of peri-implantitis were used in our experiments. The isolates were previously identified by matrix assisted laser desorption ionization-time of flight mass spectrometer (MALDI-TOF MS) (Bruker Daltonics, Bremen, Germany).

After the isolation and identification, the bacteria were stored at $-80{ }^{\circ} \mathrm{C}$ in Brain Heart Infusion (BHI) broth (Oxoid, UK) supplemented with $12 \%(\mathrm{v} / \mathrm{v})$ glycerol. The strains were incubated at $37{ }^{\circ} \mathrm{C}$ for $24 \mathrm{~h}$ in $5 \% \mathrm{CO}_{2}$ atmosphere on blood agar plate containing $5 \%$ cattle blood (BioMérieux, S. A. Marcyl'Etoile, France) for experiments.

The mono-bacterial suspension was prepared in $1 \%$ glucose bouillon from the overnight blood agar plate of each strain. After incubation at $37{ }^{\circ} \mathrm{C}$ for $3 \mathrm{~h}$ under aerobic atmosphere, enriched with $5 \% \mathrm{CO}_{2}$, the optical density (OD) of the cultures reached the 0.5 McFarland density. The bacterial suspension was pipetted on the surfaces of discs in 24-well hydrophilic surface plate (Tissue Culture 24 well plate, Sarstedt, Nümbrecht, Germany).

We used different incubation time for the two test bacteria since our goal was to investigate the response of pioneer colonizer streptococci to antiseptic treatment in distinct laboratory conditions and create basic in vitro models for our further investigations. Therefore, we used a shorter incubation time for S. mitis $(4.5 \mathrm{~h})$ similarly to our previous experiment [17] and other researchers work [18]. However, we extended the incubation time to $48 \mathrm{~h}$ in case of S. salivarius where after $24 \mathrm{~h}$ we changed the culture medium for fresh $1 \%$ glucose bouillon. This was performed based on Rath et al. in vitro biofilm model who established in their work that already $24 \mathrm{~h}$ cultivation time of S. salivarius is enough for biofilm formation on titanium implant [19].

After incubation at $37{ }^{\circ} \mathrm{C}$ in $\mathrm{CO}_{2}$ the developed biofilms were washed with $1 \times$ phosphate-buffered saline $(\mathrm{PBS})(1 \times$, pH: 7.2) to remove the less adherent cells. Than the attached bacterial cells were treated with $2 \mathrm{ml}$ of three different oral antiseptics: CHX (Curasept ADS 220, 0.2\%, Switzerland), PI (Betadine, 10\%, Switzerland), and CD (Solumium dental, $0.12 \%$, Hungary) for $5 \mathrm{~min}$, since it can be optimal in the usual dental practice according our previous results [9] and other researchers [20]. The antiseptics were washed out from the implant surfaces by rinsed them with $1 \mathrm{ml} 1 \times$ PBS.

In order to follow the metabolic activity of the bacterial biofilm 3-(4,5-dimethylthiazol-2-yl)-2,5-diphenyltetrazolium 
bromide (MTT) (Sigma-Aldrich, Darmstadt, Germany) assay was used. This method was previously tested on epithelial cell culture by our research group [11]. After the antiseptic treatment and washing steps $50 \mu \mathrm{L}$ MTT solution $(1 \mathrm{mg} / \mathrm{ml}$ final concentration) was added to $0.5 \mathrm{ml} 1 \times$ PBS on the samples and incubated at $37^{\circ} \mathrm{C}$ for $4 \mathrm{~h}$. Than the solution was removed from each well and the remaining formazan crystals, which indicates the level of cell metabolic activity, were solubilized with $200 \mu \mathrm{L}$ of $0.04 \mathrm{mM} \mathrm{HCl}$ (Scharlab, Spain) in absolute isopropanol (Molar Chemicals, Hungary) and with $40 \mu \mathrm{L}$ of $10 \%$ sodium dodecyl sulfate (Sigma-Aldrich $\mathrm{GmbH}$, Germany). The OD of solubilized formazan crystals were measured at $550 \mathrm{~nm}$ with an ELISA reader (Anthos Labtech Elisa Reader, Hungary).

The antibacterial effect of the antiseptics was compared with untreated control Ti discs with the developed biofilm which were only rinsed with sterile $1 \times \mathrm{PBS}$.

\section{Statistical analysis}

Statistical analysis was carried out using Statistica 13 (Dell Inc. USA). After test of normality (Shapiro-Wilk test) the comparisons within group were evaluated using one-way analysis of variance (ANOVA) followed by Tukey's post hoc test and T-test was used for comparison of independent samples. The means \pm SEM (standard error of the mean) were calculated for $\mathrm{OD}_{550 \mathrm{~nm}}$ values measured by plate reader based on five parallel experiments (three measures in each group) carried out in different time points. Statistical significance was set at $P<0.05$.

\section{RESULTS}

\section{Disinfectant efficacy of oral antiseptics on S. mitis biofilm determined by MTT colorimetric assay}

The results of antimicrobial activity of antiseptics against $S$. mitis are shown in Fig. 1. Evaluation of the three disinfectants antibacterial activity against the pioneer colonizer indicated that among antiseptics the PI and the CD showed significant difference both on the polished (ANOVA $P=0.0005$ ) and the sand blasted, acid etched (ANOVA $P=0.0004$ ) Ti

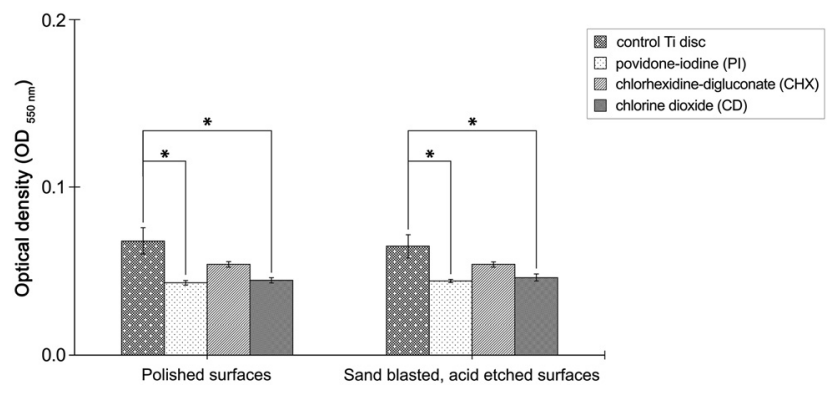

Figure 1. Determination of the antibacterial efficiency of different antiseptic agents by MTT colorimetric assay for $S$. mitis. The values were calculated from five independent experiments and are shown as mean \pm SEM. Asterisks denote significant differences $\left({ }^{\star} P<0.05\right)$ surfaces compared with the untreated control Ti discs after the 5 min treatment time. We presented the measured OD values on Fig. 1 however, we converted these data to percent values and mentioned them in this way in the text (data are not shown here). The attachment to the control Ti surface was considered $100 \%$ (highest OD value) and the number of metabolically active cells on the surfaces was expressed in relative percentages in the results section.

Based on our MTT results all antiseptic decreased the cell metabolic activity in biofilm on sand blasted, acid etched and polished surfaces. However, the PI and CD showed significant cell reduction on both surfaces $(P<0.05)$.

The PI was the most effective antiseptic against the $S$. mitis cells incubated for $4.5 \mathrm{~h}$, since it decreased the number of active cells with $37 \%\left(\mathrm{OD}_{550}=0.043 \pm 0.001\right)$ on polished surface compared with the control disc $\left(\mathrm{OD}_{550}=\right.$ $0.068 \pm 0.008)$ after 5 min treatment time $(P=0.0012)$. We observed completely similar tendency with regard the sand blasted, acid etched surfaces. The decrease of the metabolically active cells was $33 \%\left(\mathrm{OD}_{550}=0.044 \pm 0.001\right)$ after rinsing with PI compared with the untreated control Ti discs $\left(\mathrm{OD}_{550}=0.065 \pm 0.007\right)(P=0.0007)$.

\section{Disinfectant efficacy of oral antiseptics on S. salivarius biofilm determined by colorimetric MTT assay}

The disinfectants dissolving effects on S. salivarius biofilm developed for a prolonged incubation time $(48 \mathrm{~h})$ are detailed in Fig. 2. According to our results all tested agents significantly decreased the amount of metabolically active cells in S. salivarius biofilm on polished surfaces compared with the untreated $\mathrm{Ti}$ surfaces in vitro (ANOVA $P<$ $0.0001)$. The most pronounced antibacterial activity was attributed to PI, which is eliminated $65 \%(\mathrm{OD}=0.048 \pm$ 0.003 ) of biofilm forming cells on polished surface after 5 min treatment time $(P=0.0002)$. However, the $\mathrm{CD}$ also eliminated a remarkable percent of the biofilm $(60 \%)$ $(\mathrm{OD}=0.056 \pm 0.001)$ compared with the control polished discs $(\mathrm{OD}=0.139 \pm 0.01, P=0.0002)$. Considering the three agents significant differences could be observed between the PI and CHX $(P=0.0002)$ and in this respect between the $\mathrm{CD}$ and $\mathrm{CHX}(P=0.0006)$ as well.

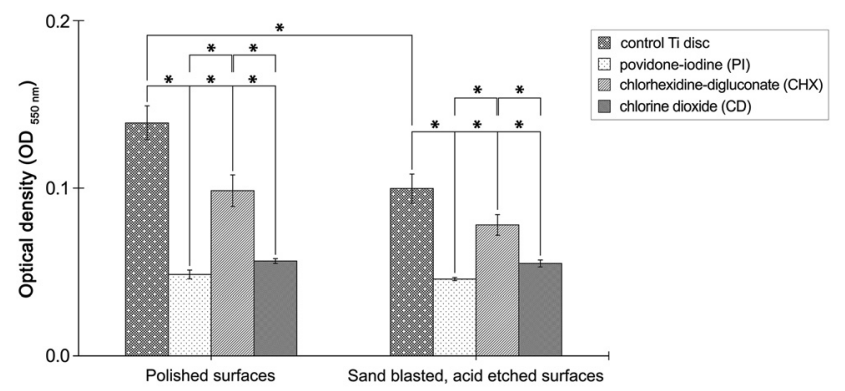

Figure 2. Effect of antiseptics on the S. salivarius cells using MTT colorimetric assay. The values were calculated from five independent experiments and are shown as mean \pm SEM. Asterisks denote significant differences $\left({ }^{\star} P<0.05\right)$ 
On the sand blasted, acid etched surface the metabolic activity of $S$. salivarius cells decreased in the biofilm when treated with all three antiseptics compared with the control discs (ANOVA $P<0.0001$ ). Furthermore, the PI and CD showed significantly higher antibacterial activity against $S$. salivarius compared with the CHX treatment (PI vs. CHX $P=0.0007$, CD vs. CHX $P=0.0212$ ).

Besides these results the quantitative evaluation of bacterial adhesion to different control Ti surfaces revealed that the density of metabolically active cell was significantly lower on the polished surface than on the sand blasted, acid etched groups, respectively $(P=0.0063)$. We did not found such difference at $S$. mitis between non treated control polished and sand blasted acid etched surfaces (Fig. 1).

\section{DISCUSSION}

In dentistry the dental implants are widely used for tooth replacement however, the implant surfaces similarly to the tooth surfaces provides possibility for attachment of bacteria and for formation of a complex biofilm which can cause inflammation around peri-implant tissues and influence the long-term success of osseointegration of implants [21].

Generally in dentistry a smooth Ti surface is developed to provide epithelial attachment and prevent plaque formation. The rough part of $\mathrm{Ti}$ implant responsible for proper connective tissue attachment, and grant the anchorage of implant in the bone. The peri-implant inflammation caused by pathogens can spread apically from the colonized neck part of $\mathrm{Ti}$ implant toward the deeper bone tissue region therefore, we used two different surface roughness of dental implant (polished and sand blasted, acid etched) to model this complex process on two test bacteria (S. mitis, S. salivarius) in our in vitro model [22].

According to McDonnell and Russell [10] CHX is one of the most well-known and widely used antiseptic agent in dentistry, but based on our results it is showed significant cell reduction only in case of $S$. salivarius after $5 \mathrm{~min}$ exposure time. The $\mathrm{CHX}$ reduced $29 \%$ of metabolically active cells while the other two agents destroyed double amount of proliferating $S$. salivarius.

Based on MTT data the PI and CD were the two most effective antiseptic agents against $S$. mitis and $S$. salivarius. Moreover, both agents are proved to be significantly better compared with CHX in the elimination of the S. salivarius biofilm developed for $48 \mathrm{~h}$. Our results are in concordance with Herczegh et al. [23] who established in their work that the $\mathrm{CD}$ was more effective compared with $\mathrm{CHX}$ after 5 min treatment time.

Our model demonstrated that the PI was the most effective in the in vitro elimination of both bacterial biofilms. However, in case of $S$. mitis we could not observe significant difference between PI and CD. Hosaka et al. [24] reported that even $0.5 \mathrm{~min}$ application of PI was effective in the in vitro killing both of Porphyromonas gingivalis and Fusobacterium nucleatum and according to other studies the CD was also effective in reducing the plaque of $F$. nucleatum. [25] Currently there are no data in the literature about the comparison of the effectiveness of PI and CD in the same in vitro experimental setting.

Besides these three antiseptics there are several other agents to control biofilm associated peri-implantitis. [10] However, choosing an ideal antiseptic to the therapy of periimplantitis is influenced not only by effectiveness but also by the lack of side effects of agent. CHX is the most widely used gold standard antiseptic for plaque control [26] but CHX have some adverse properties. It stains teeth or it can cause oral mucosa desquamation or the burning sensation of the oral mucosa $[27,28]$. However, the anti discoloration system (ADS) presented in Curasept used by our experiment can reduce the risk of discoloration and eliminates the unpleasant taste-disturbance [29]. PI has also adverse effects including allergy or hypersensitivity to the solution, and it can cause a reversible yellowish discoloration as well, however the short durations of using PI in low concentration could decrease these effects $[30,31]$. In our experiment we used a short $5 \mathrm{~min}$ exposure time, furthermore, Kanagalingam et al. reported in their review that there have been no clinical reports on development of microbial resistance after the PI treatment while, in contrast bacterial resistance to CHX has been observed [32]. Based on our MTT assay data, we determined that PI could be a promising oral antiseptic in the prevention of peri-implantitis.

According to other researchers [33] CD can react with four amino acids (cysteine, methionine, tyrosine, tryptophan) which have vital role in living organism and microbes can not develop resistance against CD, it can not cause real harm to humans as it is not able to penetrate into the deep tissues [33]. CD is effective in relatively low concentrations and the new membrane technology developed by Noszticziusz et al. [33] allows the production of high purity $\mathrm{CD}$ solution without any by-products. These properties could make it an ideal antiseptic beside PI in dental practice to treat inflammation caused by microoganisms.

\section{CONCLUSION}

In our study we compared the antimicrobial effect of three antiseptics (CHX, PI, CD) on S. mitis and S. salivarius in mono-species biofilm models adhering to Ti surfaces using MTT colorimetric assay. The antimicrobial property of all tested disinfectants have been known, however there are limited information in the literature about their comparison.

Our data indicated, that PI and CD had remarkable eliminating property against $S$. mitis and S. salivarius cells in biofilm after $5 \mathrm{~min}$ of treatment time. Considering the conflicts in available literature regarding the cytotoxic properties of agents we established that the PI and CD means advantageous disinfectants, since they are effective in vitro against the biofilms of the pioneer colonizers under aerobic conditions. 
In the light of our results we plan the further optimization of our in vitro model by using other pathogenic anaerobic bacteria or pathogenic fungal species and changing the treatment time or concentration of antiseptics for their most effective clinical application.

\section{ACKNOWLEDGMENTS}

The present study was supported by the following grants: GINOP-2.3.2-15-2016-00011- Molecular research of oral diseases. The autors are grateful to Denti System Ltd for supplying our research group with commercially pure $\mathrm{Ti}$ for the experiments.

Conflict of interest: The authors declared no potential conflicts of interest with respect to the research, authorship, and publication of this article.

\section{REFERENCES}

[1] Abrahamsson I, Berglundh T, Lindhe J. Soft tissue response to plaque formation at different implant systems. A comparative study in the dog. Clin Oral Implants Res 1998; 9: 73-73.

[2] Berglundh T, Persson L, Klinge B. A systematic review of the incidence of biological and technical complications in implant dentistry reported in prospective longitudinal studies of at least 5 years. J Clin Periodontol 2002; 29: 197-212.

[3] Dewhirst FE, Chen T, Izard J, Paster BJ, Tanner AC, Yu WH, et al. The human oral microbiome. J Bacteriol 2010; 192: 5002-17.

[4] Huang R, Li M, Gregory R. Bacterial interactions in dental biofilm. Virulence 2011; 2: 435-44.

[5] Zitzmann ZU, Berglundh T. Definition and prevalence of periimplant diseases. J Clin Periodontol 2008; 35: 286-91.

[6] Gristina A. Biomaterial-centered infection: microbial adhesion versus tissue integration. Science 1987; 237: 1588-95.

[7] Esposito M, Hirsch JM, LekholmU, ThomsenP. Failure patterns of four osseointegrated oral implant systems. J Mater Sci Mater Med 1997; 8: 812-47.

[8] Machtei EE. Treatment alternatives to negotiate peri-implantitis. Advances Med 2014; 2014: 13.

[9] Ungvari K, Pelsoczi IK, Kormos B, Oszko A, Rakonczay Z, Kemeny $L$, et al. Effects on titanium implant surfaces of chemical agents used for the treatment of peri-implantitis. J Biomed Mater Res B Appl Biomater 2010; 94: 222-9.

[10] McDonnell G, Russell AD. Antiseptics and disinfectants: activity, action, and resistance. Clin Microbiol Rev 1999; 12 147-79.

[11] Southard SR, Drisko CL, Killoy WJ, Cobb CM, Tira DE. The effect of $2 \%$ chlorhexidine digluconate irrigation on clinical parameters and the level of bacteroides gingivalis in periodontal pockets. J Periodontol 1989; 60: 302-9.

[12] Grootveld M, Silwood C, Gill D, Lynch E. Evidence for the microbicidal activity of a chlorine dioxide-containing oral rinse formulation in vivo. J Clin Dent 2001; 12: 67-70.
[13] Benarde MA, Snow WB, Olivieri VP, Davidson B. Kinetics and mechanism of bacterial disinfection by chlorine dioxide. Appl Microbiol 1967; 15: 257-65.

[14] Durani P, Leaper D. Povidone-iodine: use in hand disinfection, skin preparation and antiseptic irrigation. Int Wound J 2008; 5: 376-87.

[15] Stewart EJ. Growing unculturable bacteria. J Bacteriology 2012; 194: 4151-60.

[16] Aas JA, Paster BJ, Stokes LN, Olsen I, Dewhirst FE. Defining the normal bacterial flora of the oral cavity. J Clin Microbiol 2005; 43: 5721-32.

[17] Györgyey Á, Janovák L, Ádám A, Kopniczky J, Tóth LK, Deák Á, et al. Investigation of the in vitro photocatalytic antibacterial activity of nanocrystalline $\mathrm{TiO}_{2}$ and coupled $\mathrm{TiO}_{2} / \mathrm{Ag}$ containing copolymer on the surface of medical grade titanium. J Biomater Appl 2016; 31: 55-67.

[18] Montanaro L, Campoccia D, Rizzi S, Donati EM, Breschi L, Prati C, et al. Evaluation of bacterial adhesion of Streptococcus mutans on dental restorative materials. Biomaterials 2004; 24: 4457-63.

[19] Rath H, Stumpp NS, Stiesch M. Development of a flow chamber system for the reproducible in vitro analysis of biofilm formation on implant materials. PLoS One 2017; 12: e0172095.

[20] Schou S, Berglundh T, Lang PN. Surgical treatmnet of periimplantitis. Int J Oral Maxillofac Implants 2004; 19: 140-9.

[21] Wilson M. Bacterial biofilms and human disease. Sci prog 2001; 84: 235-54

[22] Dhir S. Biofilm and dental implant: the microbial link. J Indian Soc Periodontology 2013; 17: 5-11.

[23] Herczegh A, Gyurkovics M, Agababyan H, Ghidán Á, Lohinai Z. Comparing the efficacy of hyper-pure chlorine-dioxide with other oral antiseptics on oral pathogen microorganisms and biofilm in vitro. Acta Microbiol Immunol Hung 2013; 60: 359-73.

[24] Hosaka Y, Saito A, Maeda R, Fukaya C, Morikawa S, Makino A, et al. Antibacterial activity of povidone-iodine against an artificial biofilm of Porphyromonas gingivalis and Fusobacterium nucleatum. Arch Oral Biol 2012; 57: 364-8.

[25] Shinada K, Ueno M, Konishi C, Takehara S, Yokoyama S, Zaitsu T, et al. Effects of a mouthwash with chlorine dioxide on oral malodor and salivary bacteria: a randomized placebocontrolled 7-day trial. Trials 2010; 11: 14-14.

[26] Mathur S, Mathur T, Srivastava R, Khatri R. Chlorhexidine: the gold standard in chemical plaque control. Natl J Physiol Pharm Pharmacol 2011; 1: 45-50.

[27] Addy M, Moran J, Griffiths AA, Wills-Wood NJ. Extrinsic tooth discoloration by metals and chlorhexidine. I. Surface protein denaturation or dietary precipitation?. Br Dent J 1985; 159: 281-5.

[28] Kenrad B. Toxin effects from chlorhexidine gluconate: case report. Tandlaegebladet 1990; 94: 489-91.

[29] Marrelli M, Amantea M, Tatullo M. A comparative, randomized, controlled study on clinical efficacy and dental staining reduction of a mouthwash containing chlorhexidine $0.20 \%$ and Anti Discoloration System (ADS). Ann Stomatol (Roma) 2015; 6: 35-42.

[30] Rath T, Meissl G. Induction of hyperthyroidism in burn patients treated topically with povidone-iodine. Burns Incl Therm Inj 1988; 14: 320-2.

[31] Chua J, Dominguez E, Mae C, Sison CMC, Berba R. The efficacy of povidone-iodine oral rinse in preventing ventilator- 
associated pneumonia: a randomized, double blind, placebocontrolled (VAPOR) trial: preliminary report. Philipp J Microbiol Infect Dis 2004; 33: 153-61.

[32] Kanagalingam J, Feliciano R, Hah JH, Labib H, Le TA, Lin JC. Practical use of povidone-iodine antiseptic in the maintenance of oral health and in the prevention and treatment of common oropharyngeal infections. Int J Clin Pract 2015; 69: 1247-56.

[33] Noszticzius Z, Wittmann M, Kaly-Kullai K, Beregvari Z, Kiss I, Rosivall $\mathrm{L}$, et al. Chlorine dioxide is a size-selective antimicrobial agent. PLoS One 2013; 8: e79157.

This is an open-access article distributed under the terms of the Creative Commons Attribution 4.0 International License (https://creativecommons.org/licenses/by/4.0/), which permits unrestricted use, distribution, and reproduction in any medium, provided the original author and source are credited, a link to the CC License is provided, and changes - if any - are indicated. (SID_1) 